\title{
Erratum to: Prognostication of OCT4 isoform expression in prostate cancer
}

\author{
Marina França de Resende • Ludmilla Thomé Domingos Chinen • \\ Samantha Vieira • Juliano Jampietro • Francisco Paulo da Fonseca • \\ José Vassallo • Luciene Cristina Campos • Gustavo Cardoso Guimarães • \\ Fernando Augusto Soares $\cdot$ Rafael Malagoli Rocha
}

Published online: 1 December 2013

(C) International Society of Oncology and BioMarkers (ISOBM) 2013

Erratum to: Tumor Biol 34 (5): 2665-2673

DOI 10.1007/s13277-013-0817-9

The authors apologize for omission of the following reference:

"de Resende MF, Vieira S, Chinen LT, Chiappelli F, da Fonseca FP, Guimarães GC, et al. Prognostication of prostate cancer based on TOP2A protein and gene assessment: TOP2A in prostate cancer. J Transl Med. 2013; 11:36.”

This reference should have been included after the first paragraph of "Materials and Methods" "Tumor samples and clinical data"; and after the first paragraph of "Results" "Patients".

Image $\mathrm{C}$ of Figure 5 has been selected by mistake from the same file as Image A from the same Figure.

The correct figure is the following:

The online version of the original article can be found at http://dx.doi.org/ 10.1007/s13277-013-0817-9.

M. F. de Resende $\cdot$ S. Vieira $\cdot$ J. Jampietro $\cdot$ J. Vassallo $•$

F. A. Soares $\cdot$ R. M. Rocha $(\bowtie)$

Department of Anatomic Pathology, A.C. Camargo Cancer Hospital,

Rua Professor Antônio Prudente 211, Liberdade,

Sao Paulo, SP 01509-900, Brazil

e-mail: rafael.malagoli@gmail.com

\section{T. D. Chinen}

Department of Clinical Oncology, A.C. Camargo Cancer Hospital,

Sao Paulo, Brazil

F. P. da Fonseca • G. C. Guimarães

Department of Urology, A.C. Camargo Cancer Hospital,

Sao Paulo, Brazil

\section{C. Campos}

Laboratory of Genetics and Molecular Cardiology,

Heart Institute (InCor), University of Sao Paulo Medical School,

Sao Paulo, Brazil 

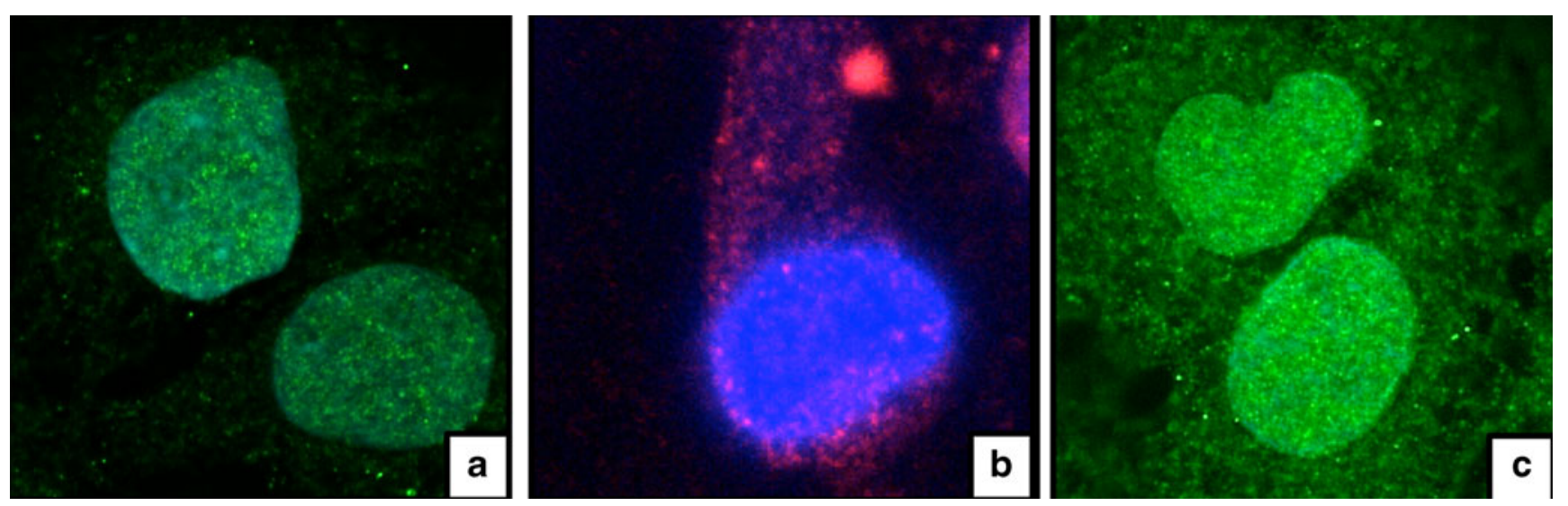

Fig. 5 Immunofluorescence by confocal microscopy at x1000 magnification showing cell localization of protein expression. OCT4A nuclear positivity (a), OCT4B cytoplasmic positivity (b), and OCT4 nuclear and cytoplasmic positivity (c) in the prostate cancer cell line DU-145 